\title{
Epidemiologic factors that predict long-term survival following a diagnosis of epithelial ovarian cancer
}

Shana J Kim ${ }^{1,2}$, Barry Rosen ${ }^{3,4}$, Isabel Fan ${ }^{5}$, Anna Ivanova ${ }^{1,6}$, John R McLaughlin ${ }^{5,7}$, Harvey Risch ${ }^{8}$, Steven A Narod ${ }^{1,6}$ and Joanne Kotsopoulos ${ }^{\star 1,2,6}$

${ }^{1}$ Women's College Research Institute, Women's College Hospital, 76 Grenville, Toronto, ON, Canada; ${ }^{2}$ Department of Nutritional Sciences, University of Toronto, Toronto, ON, Canada; ${ }^{3}$ Princess Margaret Cancer Centre, University Health Network, 610 University Avenue, Toronto, ON, Canada; ${ }^{4}$ Division of Gynecologic Oncology, Department of Obstetrics and Gynecology, University of Toronto, 610 University Avenue, Toronto, ON, Canada; ${ }^{5}$ Samuel Lunenfeld Research Institute, Mount Sinai Hospital, Joseph and Wolf Lebovic Health Complex, 600 University Avenue, Toronto, ON, Canada; ${ }^{6}$ Dalla Lana School of Public Health, University of Toronto, 155 College Street, Health Science Building, Toronto, ON, Canada; ${ }^{7}$ Public Health Ontario, Toronto, ON, Canada and ${ }^{8}$ Department of Chronic Disease Epidemiology, Yale School of Public Health, 60 College Street, New Haven, CT, USA

Background: Various epidemiologic factors have been shown to influence the risk of ovarian cancer development. Given the high fatality associated with this disease, it is of interest to evaluate the association of prediagnostic hormonal, reproductive, and lifestyle exposures with ovarian cancer-specific survival.

Methods: We included 1421 patients with invasive epithelial ovarian cancer diagnosed in Ontario, Canada. Clinical information was obtained from medical records and prediagnostic exposure information was collected by telephone interview. Survival status was determined by linkage to the Ontario Cancer Registry. Proportional hazards regression was used to estimate hazard ratios (HRs) and 95\% confidence intervals (Cls) for ovarian cancer-specific mortality associated with each exposure. Analyses were stratified by histologic subtype to further investigate the associations of risk factors on ovarian cancer-specific mortality.

Results: After a mean follow-up of 9.48 years (range 0.59-20.32 years), 655 (46\%) women had died of ovarian cancer. Parity (ever) was associated with a significant $29 \%$ decreased mortality risk compared with nulliparity ( $H R=0.71 ; 95 \% \mathrm{Cl} 0.54-0.93 ; P=0.01)$. There was a borderline significant association between ever use of oestrogen-containing hormone replacement therapy (HRT) and mortality ( $\mathrm{HR}=0.79 ; 95 \% \mathrm{Cl} 0.62-1.01 ; P=0.06)$. A history of cigarette smoking was associated with a significant $25 \%$ increased risk of death compared with never smoking $(H R=1.25 ; 95 \% \mathrm{Cl} 1.01-1.54 ; P=0.04)$. Women with a greater cumulative number of ovulatory cycles had a significantly decreased risk of ovarian cancer-specific death ( $H R=0.63 ; 95 \% \mathrm{Cl} 0.43-0.94 ; P=0.02)$. Increasing BMI $\left(\mathrm{kg} \mathrm{m}^{-2}\right) 5$ years before diagnosis was associated with an increased risk of death $(\mathrm{HR}=1.17 ; 95 \% \mathrm{Cl} 1.07-1.28$; $P=0.0007)$. Other hormonal or lifestyle factors were not significantly associated with ovarian cancer-specific mortality.

Conclusions: Parity, ovulatory cycles, smoking, and BMI may affect survival following the diagnosis of ovarian cancer. Whether or not oestrogen-containing HRT use is beneficial for survival requires further evaluation.

*Correspondence: Dr J Kotsopoulos; E-mail: joanne.kotsopoulos@wchospital.ca

Received 14 November 2016; revised 19 January 2017; accepted 23 January 2017; published online 16 February 2017

(C) 2017 Cancer Research UK. All rights reserved 0007-0920/17 
Cancer of the ovary is the most fatal gynaecologic malignancy and is the fifth leading cause of cancer related death among women in Canada and the United States (Sopik et al, 2015). Although the pathogenesis of ovarian cancer is not clearly understood, proposed mechanisms include the 'incessant ovulation hypothesis,' whereby factors that suppress or interrupt ovulation protect against ovarian cancer (Fathalla, 1971; Ness et al, 2000; Fleming et al, 2006). Other proposed mechanisms of ovarian cancer carcinogenesis include stimulation by hormonal exposures, inflammation mechanisms, and retrograde transportation of endogenous or exogenous carcinogens through the fallopian tubes (Cramer et al, 1982; Cramer and Xu, 1995; Risch, 1998; Ness and Cottreau, 1999; Shan and Liu, 2009). These hypotheses are supported by epidemiologic findings of ovarian cancer risk reduction with events that interrupt or suppress ovulation (e.g., pregnancy and oral contraceptive use; Whittemore et al, 1992; Danforth et al, 2007; Beral et al, 2008; Luan et al, 2013), reduce inflammation (e.g., aspirin or non-aspirin NSAID use, tubal ligation; Trabert et al, 2014), whereas exposures that increase inflammation (e.g., endometriosis; Pearce et al, 2012; Terry et al, 2013) or hormonal exposure (e.g., exogenous hormone use) are associated with an increased risk (Zhou et al, 2008).

The prognosis of ovarian cancer is poor with a mean 5 -year survival of $45 \%$ and $15-25 \%$ among stage III/IV patients (Sopik et al, 2015). Clinical factors that influence survival include stage at detection, volume of disease, success in optimal debulking, histologic subtype, tumour grade, and response to chemotherapy (Barakat et al, 2009; du Bois et al, 2009; Chang and Bristow, 2012). The influence of additional lifestyle factors such as body mass index (BMI) have been inconsistent as some evidence suggests higher BMI is associated with adverse prognosis and increased ovarian cancer mortality (Poole et al, 2016); however, these findings contrast previous reports of no association between body size and ovarian cancer survival (Kotsopoulos et al, 2012; Zhou et al, 2014). In a recent previous study, we found that the most important prognostic factor was the absence of residual tumour following primary debulking surgery, irrespective of other tumour characteristics (Kotsopoulos et al, 2016). Given that the mortality associated with ovarian cancer has changed little in recent years, it is of interest to evaluate whether or not epidemiologic factors associated with risk of ovarian cancer may also influence outcome from this fatal disease.

Various studies have evaluated roles of hormonal, reproductive, and lifestyle factors on the prognosis of ovarian cancer; however, findings have been inconclusive and many analyses were limited by a small number of patients, relatively short follow-up periods, and other methodologic concerns (recently reviewed in Poole et al, 2016). Using a large sample of patients with ovarian cancer, many followed for a decade or more, we evaluated the association between prediagnostic epidemiologic factors and long-term ovarian cancer-specific mortality.

\section{MATERIALS AND METHODS}

Study population. The current study uses information from a large series of unselected ovarian cancer patients diagnosed in Ontario, Canada. Detailed information about the study design and data collection has been previously published (Zhang et al, 2011; McLaughlin et al, 2013; Narod et al, 2013). Briefly, all residents between the ages of 20 and 79 years with diagnoses of new invasive epithelial ovarian cancer from January 1995 to December 1999 and from January 2002 to December 2004 were identified through the Ontario Cancer Registry (OCR) (Zhang et al, 2011; McLaughlin et al, 2013; Narod et al, 2013). Of the 3168 initially eligible patients, genetic testing was performed on 1421 (45\%), as previously described, and these are the subjects included in the present study
(Zhang et al, 2011). The mean time between date of diagnosis and date of genetic testing was 1.83 years. All of the women provided written informed consent and the study was approved by the institutional review boards of the University of Toronto and Yale University.

Pathology review and outcome data. For each patient, the investigators reviewed pathology records to determine eligibility and tumour histology. Medical records were reviewed to obtain information about clinical staging, treatments received, and treatment outcomes. Extent of residual disease following primary debulking surgery was coded as 'yes' (presence of any residual disease) or 'no' (zero residual disease). Survival status was determined both by periodic chart review at local hospitals and computerised linkage to the records of the OCR that provides information on fact, date, and cause of death. The OCR, which began in 1964, contains highly complete information on cancer incidence, mortality, and survival in Ontario. We used vital status and cause of death obtained from a linkage performed with data in the OCR on 1 May 2015. For the purpose of this analysis, cause of death was coded as ovarian cancer or other.

Assessment of epidemiologic risk factors and covariates. Information on known and suspected ovarian cancer risk factors and demographic information was collected by telephone interview with a standardised-script questionnaire. Specifically, detailed data were obtained for age at menarche, age at menopause, parity, breastfeeding (number of months), oral contraceptives use, oestrogencontaining hormone replacement therapy (HRT), infertility treatment, smoking history, tubal ligation, intrauterine device (IUD) use, family history of breast or ovarian cancer, and endometriosis. The cumulative number of ovulatory cycles for each woman was estimated using the following equations: (1) if premenopausal: ovulatory cycles $=12 \times($ current age - age at menarche - years of oral contraceptive use $-($ parity $\times 0.77)-$ years of breastfeeding); (2) if postmenopausal, current age was replaced with age at menopause (surgical or natural). Participants also reported their current weight and height, height and weight at age 21 years, and weight 5 years before their diagnosis. Body mass index at various ages was calculated in units of $\mathrm{kg} \mathrm{m}^{-2}$ using the reported current height. To avoid the influence of disease status on body weight, we calculated BMI $(n=1316)$ in units of $\mathrm{kg} \mathrm{m}^{-2}$ using reported current height but weight 5 years in the past. The mean number of months elapsed from date of diagnosis to the date of interview was 22.0 months (range 0.1-79 months).

Statistical analysis. Differences between clinical, demographic, and other characteristics were compared according to cause of death at the end of follow-up using the $\chi^{2}$ test or $t$-test, as appropriate. The primary outcome in this analysis was ovarian cancer-specific survival defined as the duration from the date of diagnosis until the date of death from ovarian cancer. Survival was censored at death from another cause or 1 May 2015, the most recent limit of available death-certificate information (if patient was still alive). We performed a left-truncated survival analysis to account for the time elapsed between the date of diagnosis and the date of ascertainment (i.e., enrolment for genetic testing). This method of adjustment has been previously shown to reduce the extent of survivorship bias present in the current study population (Narod et al, 2013). Proportional hazards models were used to estimate hazard ratios (HRs) and 95\% confidence intervals (CIs) associated with the epidemiologic risk factors. The base model (model 1) was adjusted for age at diagnosis (continuous), histologic subtype (serous, mucinous, endometrioid, clear cell, and other (mixed histology and epithelial not otherwise specified)), and stage (I, II, III, IV). Twenty-seven patients had missing information on tumour stage, and thus the total number of ovarian cancer cases in model 1 was 1394 . Model 2 adjusted for the covariates in model 1 
as well as for residual disease status (yes or no), in which 588 participants had missing information, and thus the total number of ovarian cancer cases in model 2 was 833 . Each exposure variable of interest was added to the models one at a time. Proportional hazards assumptions were assessed with Schoenfeld and Martingale residuals (Allison, 1995). The statistical significance of interaction terms between histologic subtypes and various exposures were determined using the likelihood ratio test. Stratified analyses were conducted for significant interaction terms to further investigate the role of histological subtype on various exposures. Analyses were performed using SAS version 9.4 (SAS Institute, Cary, NC, USA) and all $P$-values are two sided.

\section{RESULTS}

Characteristics of the 1421 women diagnosed with invasive epithelial ovarian cancer are displayed in Table 1 by cause of death. An average of 9.48 years (range 0.59-20.32 years) of followup elapsed. Women who died of ovarian cancer had a shorter mean follow-up period, were older on average, and more likely to be diagnosed with serous, stage III, or stage IV tumours compared with women who did not die of ovarian cancer $(P<0.0001)$. Among women with information on the extent of residual disease following primary debulking surgery $(n=833 ; 59 \%)$, those who died of ovarian cancer were more likely to have residual disease compared with patients who were still alive $(P<0.0001)$. With respect to reproductive and hormonal exposures, women who died of ovarian cancer during the follow-up period were less likely to have used oral contraceptives, more likely to have used HRT, had higher mean parity, and higher mean number of ovulatory cycles compared with participants who did not die of ovarian cancer $(P<0.04)$. Women who died of ovarian cancer were more likely to have a history of cigarette smoking, a higher BMI 5 years before diagnosis, and were more likely to carry an inherited $B R C A 1$ or $B R C A 2$ mutation $(P<0.04)$. No other significant differences were found between the two groups of women.

We next evaluated the role of various epidemiologic exposures on the prognosis of ovarian cancer (Tables 2 and 3). Table 2 summarises the HRs and 95\% CIs for ovarian cancer-specific survival by various reproductive and hormonal factors. Model 1 adjusted for age, tumour histology, and grade $(n=1394)$ and model 2 was further adjusted for residual disease status $(n=833)$. Parity was associated with decreased ovarian cancer-specific mortality compared with nulliparity $\left(\mathrm{HR}_{\text {Model } 1}=0.82 ; 95 \% \mathrm{CI}\right.$ $0.66-1.02 ; P=0.07)$ and reached significance after further adjusting for residual disease $\left(\mathrm{HR}_{\text {Model } 2}=0.71 ; 95 \%\right.$ CI $0.54-0.93$; $P=0.01)$. In the same way, after additionally adjusting for residual disease, women with a greater cumulative number of ovulatory cycles had a significantly decreased risk of death from ovarian cancer $\left(>439.42\right.$ cycles $v s \leqslant 322.28$ cycles $\mathrm{HR}_{\text {Model } 2}=0.63 ; 95 \%$ CI $0.43-0.94 ; P=0.02$ ). No significant associations between the other reproductive or hormonal characteristics and mortality were observed in this cohort of ovarian cancer patients.

Associations between various lifestyle and family history characteristics and ovarian cancer survival are displayed in Table 3. Women who reported a history of cigarette smoking had increased ovarian cancer-specific mortality compared with never smokers $\left(\mathrm{HR}_{\text {Model } 1}=1.16\right.$; $95 \%$ CI $\left.0.99-1.36 ; P=0.08\right)$ and this association was stronger in the model that further adjusted for residual disease status $\left(\mathrm{HR}_{\text {Model }}{ }_{2}=1.25 ; 95 \%\right.$ CI $1.01-1.54$; $P=0.04$ ). Moreover, increasing BMI 5 years before diagnosis by 5 -unit increments was associated with an increased risk for ovarian cancer-specific mortality, both in model $1\left(\mathrm{HR}_{\text {Model } 1}=1.11 ; 95 \%\right.$ CI $1.03-1.19 ; P=0.006)$ and model $2\left(\mathrm{HR}_{\text {Model } 2}=1.17 ; 95 \% \mathrm{CI}\right.$ $1.07-1.28 ; \quad P=0.0007)$. Similarly, obesity $\left(\mathrm{BMI} \geqslant 30 \mathrm{~kg} \mathrm{~m}^{-2}\right.$ )
Table 1. Baseline characteristics of study population by ovarian cancer-specific survival

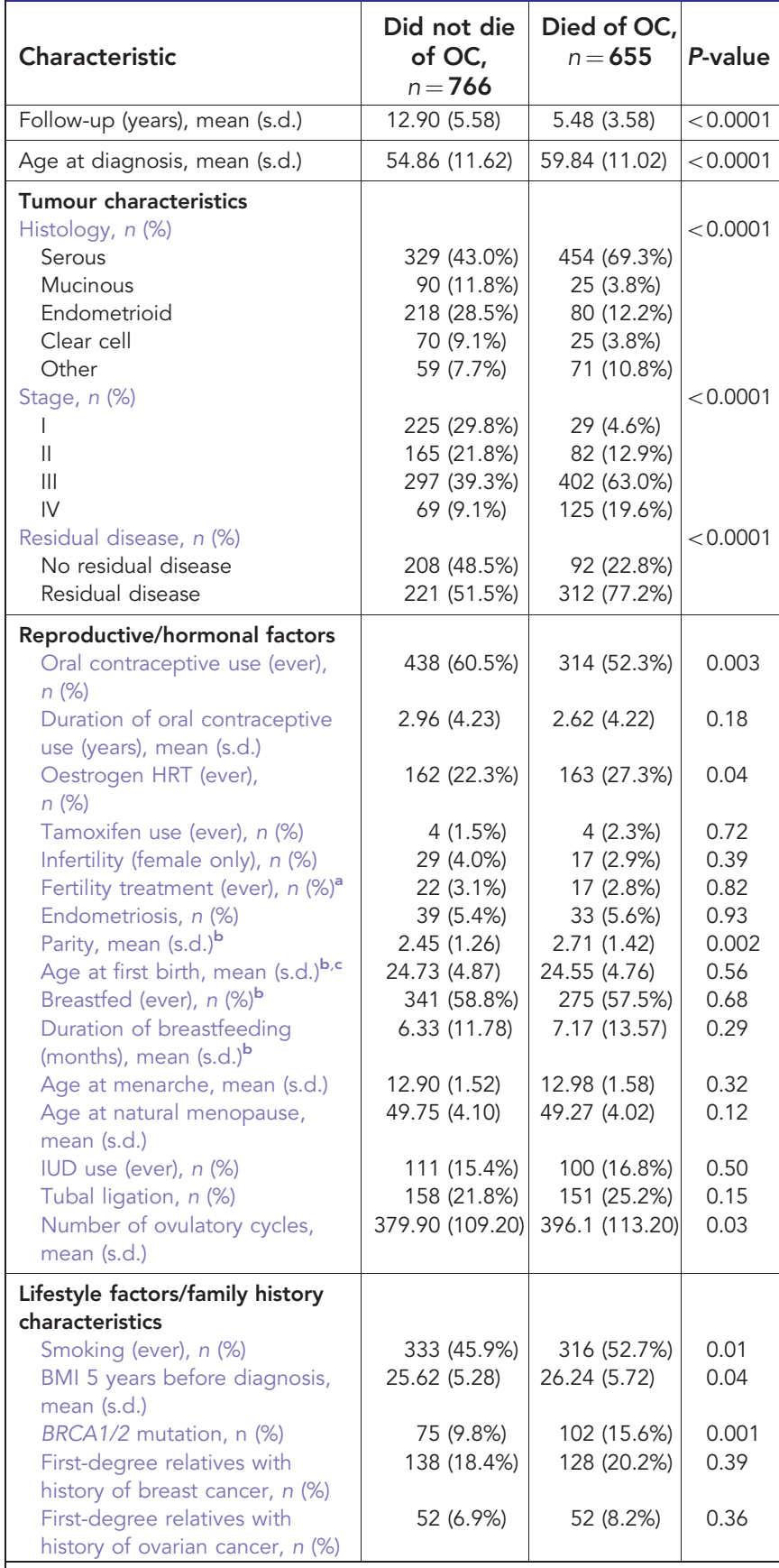

Abbreviations: $\mathrm{BMI}=$ body mass index; HRT=hormone replacement therapy; IUD = intrauterine device; $\mathrm{OC}=$ ovarian cancer.

${ }^{a_{F}}$ ertility treatment included one or more of Clomid, Serophene, Pergonal, Metrodin, Profasil, Lupron, Leuprolide, or other fertility medication.

${ }^{\mathbf{b}}$ Among parous women only.

${ }^{\mathrm{c}}$ Age at first birth based on year of birth, not exact date because of data limitations.

5 years before diagnosis was associated with an increased risk for ovarian cancer-specific mortality after additionally adjusting for residual disease $\left(\mathrm{HR}_{\text {Model } 2}=1.34 ; 95 \%\right.$ CI $1.02-1.76 ; P=0.04$ ).

Analyses were stratified by histologic subtype to further investigate the associations of risk factors on distinct subtypes, although these analyses were limited by the small number of cases in the subgroups and we did not adjust for residual disease status. The impact of smoking on death was stronger for women with a mucinous tumour $(\mathrm{HR}=2.52 ; 95 \% \mathrm{CI} 1.01-6.33 ; P=0.05) v s$ a serous $(\mathrm{HR}=1.12 ; 95 \% \mathrm{CI} 0.92-1.36 ; P=0.28)$ or an endometrioid 
Table 2. Association between reproductive and hormonal exposures and ovarian cancer-specific survival

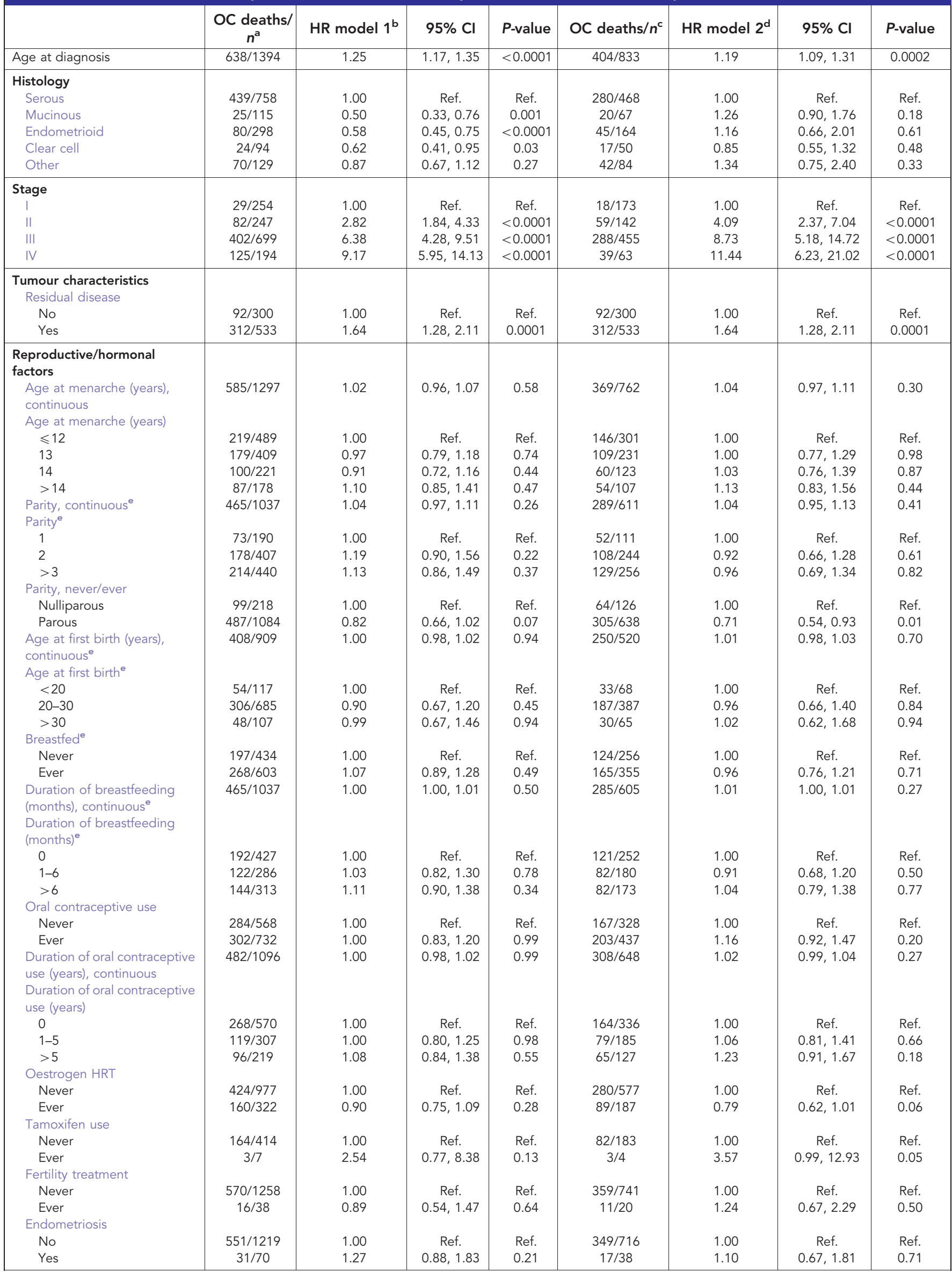




\begin{tabular}{|c|c|c|c|c|c|c|c|c|}
\hline & $\begin{array}{c}\text { OC deaths/ } \\
n^{\text {a }}\end{array}$ & HR model $1^{\mathrm{b}}$ & $95 \% \mathrm{Cl}$ & $P$-value & OC deaths $/ n^{c}$ & HR model $2^{d}$ & $95 \% \mathrm{Cl}$ & $P$-value \\
\hline $\begin{array}{l}\text { Age at natural menopause } \\
\text { (years), continuous } \\
\text { Age at natural menopause }\end{array}$ & $341 / 692$ & 0.98 & $0.96,1.01$ & 0.11 & $208 / 403$ & 0.98 & $0.94,1.01$ & 0.14 \\
\hline$\leqslant 47$ & $97 / 175$ & 1.00 & Ref. & Ref. & $55 / 99$ & 1.00 & Ref. & Ref. \\
\hline$>47-50$ & $118 / 228$ & 0.89 & $0.68,1.17$ & 0.41 & $78 / 138$ & 0.94 & $0.66,1.34$ & 0.74 \\
\hline$>50-52$ & $61 / 147$ & 0.78 & $0.56,1.07$ & 0.12 & $36 / 87$ & 0.74 & $0.48,1.14$ & 0.17 \\
\hline Premenopausal & $131 / 370$ & 1.00 & Ref. & Ref. & $89 / 211$ & 1.00 & Ref. & Ref. \\
\hline Postmenopausal & $449 / 907$ & 1.01 & $0.77,1.32$ & 0.97 & $278 / 542$ & 0.96 & $0.69,1.35$ & 0.83 \\
\hline \multicolumn{9}{|l|}{ IUD use } \\
\hline Never & $487 / 1090$ & 1.00 & Ref. & Ref. & $306 / 638$ & 1.00 & Ref. & Ref. \\
\hline Ever & $98 / 206$ & 1.09 & $0.87,1.36$ & 0.45 & $63 / 122$ & 1.06 & $0.80,1.40$ & 0.71 \\
\hline \multicolumn{9}{|l|}{ Tubal ligation } \\
\hline$>389.52-439.42$ & $101 / 225$ & 0.78 & $0.58,1.05$ & 0.10 & $62 / 133$ & 0.74 & $0.50,1.08$ & 0.12 \\
\hline$>439.42$ & $102 / 225$ & 0.82 & $0.60,1.11$ & 0.20 & $65 / 143$ & 0.63 & $0.43,0.94$ & 0.02 \\
\hline 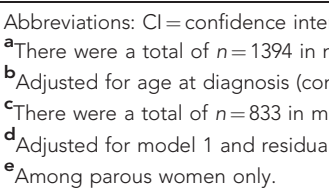 & $\begin{array}{l}\mathrm{HR}=\text { hazard ratio; } \\
\text { el } 1 \text { because } 27 \mathrm{pz} \\
\text { us), histology (se } \\
2 \text { because } 588 \mathrm{pz} \\
\text { ease (no residual }\end{array}$ & $\begin{array}{l}\text { HRT = hormone repl } \\
\text { ticipants had missing } \\
\text { ous, mucinous, endor } \\
\text { ticipants had missing } \\
\text { sease, any residual d }\end{array}$ & $\begin{array}{l}\text { ement therapy } \\
\text { nformation on } \\
\text { etrioid, clear c } \\
\text { nformation on } \\
\text { ease). }\end{array}$ & $\begin{array}{l}\text { IUD = intraut } \\
\text { umour stage } \\
\text { l, other), ano } \\
\text { esidual disea }\end{array}$ & $\begin{array}{l}\text { rine device; } \mathrm{OC}=\text { ova } \\
\text { tage }(I, I I, I I I, I V) \text {. } \\
\text { after debulking surg }\end{array}$ & $\begin{array}{l}\text { ian cancer; ref. = refe } \\
\text { ry. }\end{array}$ & ce value. & \\
\hline
\end{tabular}

$(\mathrm{HR}=0.92 ; 95 \%$ CI $0.58-1.45 ; P=0.71)$ tumour. The interaction was not statistically significant $(P$-interaction $=0.13)$. Increasing BMI (per 5-unit increase) was associated with increased mortality for women diagnosed with a serous $(\mathrm{HR}=1.09 ; 95 \%$ CI $1.00-1.19$; $P=0.05)$ and endometrioid ( $\mathrm{HR}=1.18 ; 95 \%$ CI $0.98-1.43$; $P=0.09)$ tumour, but was not significantly associated with death among women with a mucinous tumour $(\mathrm{HR}=1.14$; $95 \% \mathrm{CI} 0.72$ $1.81 ; P=0.56) \quad(P$-interaction $=0.02)$. None of the other risk factors associations varied by histologic subtype.

\section{DISCUSSION}

The goal of the current study was to evaluate associations between reproductive, hormonal, and lifestyle factors before diagnosis of epithelial ovarian cancer on survival among 1394 women. After accounting for known clinical prognostic factors (i.e., age, tumour histology, grade, and presence of residual disease), we observed that parity and greater number of ovulatory cycles were associated with better prognosis, whereas higher BMI and a history of smoking had a significant adverse effect. No other reproductive and hormonal factors were significantly associated with outcome, although we observed a borderline decreased risk of death with use of oestrogen-containing HRT. Some of the associations varied by histologic subtype, although our stratified analyses were limited by small numbers in the subgroups. Collectively, these findings suggest that although various exposures may be associated with ovarian cancer development (e.g., oral contraceptive use), the majority of these have little impact on long-term ovarian cancer outcomes.

Poole et al (2016) recently conducted an extensive review of the published literature on the prognostic associations of reproductive, hormonal, and lifestyle factors for ovarian cancer Many of the early studies included small numbers of cases, did not have information on ovarian cancer-specific survival, and did not adjust for important confounders, particularly residual disease status. The authors of the review concluded that overall the data were sparse, and whereas reproductive or hormonal factors were likely not strong predictors of outcome, body size was among the most studied and represented a lifestyle factor that may favourably influence prognosis. Since this review, one additional work evaluated the association of reproductive and hormonal factors on survival, in data from the New England Case-Control Study of Ovarian Cancer that included prediagnostic information on 1649 ovarian cancer patients and 911 all-cause deaths and reported improved survival for endometriosis and for HRT use (Shafrir et al, 2016).

In the current study, parity per se (but not increasing parity or age at first birth) was associated with better prognosis in contrast to most previous studies that have generally shown no significant association between parity and survival (Besevic et al, 2015; Poole et al, 2016; Shafrir et al, 2016). Recent observational studies have shown that parity is associated with decreased risk of type I tumours (i.e., low-grade subtypes; Fortner et al, 2015) as well as with less aggressive subtypes (i.e., survived $\geqslant 3$ years; Poole et al, 2013). Thus, parity may be associated with the development of less aggressive subtypes and, subsequently, better outcome. However, because of our small sample size in stratified analyses, whether or not parity has an association with survival after tumour characteristics have been considered is uncertain.

Although of borderline significance, we also observed a survival benefit with ever use of oestrogen-containing HRT. We did not have specific information on combined HRT regimens (i.e., oestrogen and progesterone). Eight published observational studies have examined HRT use before diagnosis and survival. These studies ranged in size from 72 to 1649 patients, with only 3 studies adjusting for residual disease in their analysis (Poole et al, 2016; Shafrir et al, 2016). Findings have been inconclusive. In the largest of these studies, Shafrir et al (2016) reported a significant survival advantage among women with $\geqslant 5$ years of HRT use before diagnosis (HR for $\geqslant 5$ years $v s$ never use $=0.79$; 95\% CI $0.55-0.90$ ). The authors did not distinguish between types of hormonal preparations. In an analysis of the EPIC study $(n=1025$ cases/511 
Table 3. Association between lifestyle factors and family history and ovarian cancer-specific survival

\begin{tabular}{|c|c|c|c|c|c|c|c|c|}
\hline & OC deaths $/ n^{a}$ & HR model $1^{b}$ & $95 \% \mathrm{Cl}$ & $P$-value & OC deaths $/ n^{c}$ & HR model $2^{d}$ & $95 \% \mathrm{Cl}$ & $P$-value \\
\hline \multicolumn{9}{|l|}{ Lifestyle factors/family history } \\
\hline Never & $274 / 661$ & 1.00 & Ref. & Ref. & 159/372 & 1.00 & Ref. & Ref. \\
\hline \multicolumn{9}{|l|}{$\begin{array}{l}\left(\mathrm{kg} \mathrm{m}^{-2}\right) \text {, continuous (5-unit } \\
\text { increases) } \\
\text { BMI } 5 \text { years before diagnosis } \\
\left(\mathrm{kg} \mathrm{m}^{-2}\right)\end{array}$} \\
\hline $18.5-<25$ & $288 / 660$ & 1.00 & Ref. & Ref. & $178 / 383$ & 1.00 & Ref. & Ref. \\
\hline $25-<30$ & $179 / 388$ & 1.10 & $0.92,1.33$ & 0.30 & $112 / 229$ & 1.13 & $0.89,1.44$ & 0.31 \\
\hline$\geqslant 30$ & $107 / 226$ & 1.22 & $0.97,1.52$ & 0.08 & $72 / 137$ & 1.34 & $1.02,1.76$ & 0.04 \\
\hline \multicolumn{9}{|l|}{ BRCA $1 / 2$ mutation } \\
\hline No & $539 / 1224$ & 1.00 & Ref. & Ref. & $341 / 725$ & 1.00 & Ref. & Ref. \\
\hline Yes & $99 / 170$ & 1.19 & $0.95,1.48$ & 0.13 & $63 / 108$ & 1.05 & $0.80,1.40$ & 0.72 \\
\hline \multicolumn{9}{|l|}{$\begin{array}{l}\text { First-degree relative with breast } \\
\text { cancer }\end{array}$} \\
\hline No & $568 / 1259$ & 1.00 & Ref. & Ref. & $362 / 754$ & 1.00 & Ref. & Ref. \\
\hline Yes & $52 / 102$ & 1.05 & $0.79,1.40$ & 0.73 & $32 / 59$ & 1.03 & $0.71,1.48$ & 0.89 \\
\hline \multirow{2}{*}{\multicolumn{9}{|c|}{$\begin{array}{l}\text { Abbreviations: } \mathrm{BMI}=\text { body mass index; } \mathrm{Cl}=\text { confidence interval; } \mathrm{HR}=\text { hazard ratio; } \mathrm{OC}=\text { ovarian cancer; ref. }=\text { reference value. } \\
\text { a There were a total of } n=1394 \text { in model } 1 \text { because } 27 \text { participants had missing information on tumour stage. }\end{array}$}} \\
\hline & & & & & & & & \\
\hline djusted for age at diagnosis (cont & , histology (se & & oid, clear c & (1) & $(I, I I, I I I, I V)$. & & & \\
\hline here were a total of $n=833$ in & 5 & & & & . & & & \\
\hline
\end{tabular}

ovarian cancer deaths), Besevic et al (2015) also reported a significant survival benefit among women with long-term use of HRT (HR for $\geqslant 5$ years $v s$ never use $=0.70 ; 95 \%$ CI $0.50-0.99 ; P$ trend $=0.04)$. However, this study did not take into account residual disease. Although the data from the larger studies suggest a survival advantage among women with histories of HRT use, these findings must be interpreted with caution given that a recent meta-analysis of 52 epidemiologic studies reported a significant increased risk of developing ovarian cancer with current use of HRT (oestrogen and oestrogen plus progesterone combinations) and increasing duration of use, particularly for serous and endometrioid subtypes (Collaborative Group on Epidemiological Studies of Ovarian Cancer et al, 2015).

In addition, although we observed improved survival among women with the highest quartile of lifetime ovulatory cycles, this finding should also be interpreted with caution given that factors that suppress or interrupt ovulation (e.g., parity, oral contraceptive use) have consistently been shown to reduce risk of ovarian cancer (La Vecchia, 2016). In addition, we did not have information on menstrual irregularity and may have overestimated the lifetime ovulatory cycles and an inflated risk estimate (Moorman et al, 2002). Furthermore, others have generally shown no association with increasing ovulatory years or cycles (Nagle et al, 2008; Robbins et al, 2009; Besevic et al, 2015; Shafrir et al, 2016). In line with the published literature to date, we found no significant associations between any of the other prediagnostic reproductive or hormonal exposures and mortality (Poole et al, 2016; Shafrir et al, 2016).

Smoking is a risk factor for mucinous ovarian cancer (Wentzensen et al, 2016). In the current study, we observed that women who reported a history of smoking (at least 100 cigarettes in their lifetime) had a significant $25 \%$ increased risk of ovarian cancer death compared with women who never smoked $(P=0.04)$. The effect was stronger among women diagnosed with a mucinous tumour. Five studies have reported on smoking and ovarian cancer survival (range 130-676 cases) (Poole et al, 2016). Collectively, the data suggest that recent or current smoking is associated with worse prognosis representing an important modifiable lifestyle factor that negatively affects outcome.

In the current study, increasing BMI was associated with a worse outcome, and the relationship was stronger among women with a serous or endometrioid tumour. These findings are in line with the majority of the published literature that have reported significant and adverse associations of adiposity with ovarian cancer prognosis (Poole et al, 2016), but the literature remains inconstant. Several reasons that may account for these discrepancies include small sample size, adjustment for important confounding factors such as residual disease, and the issue of assessing body size. Furthermore, our findings contrast our previous report of no association between body size and ovarian cancer survival within the same study population (Kotsopoulos et al, 2012). This latter discrepancy may be because of the shorter follow-up period in our earlier publication (7.4 vs 9.5 years).

Achieving no residual disease at surgical resection is likely the most important predictor of long-term survival (Chang et al, 2015). Among the patients in this study, we have recently published that women with no residual disease following primary debulking surgery experience significantly superior survival compared with patients with residual disease (Kotsopoulos et al, 2016). These observations support the notion that survival is optimised when residual disease is minimised through complete resection and chemotherapy (Narod, 2015).

The strengths and limitations of this study need to be considered. Despite the large number of unselected ovarian cancer patients, we were not sufficiently powered to conduct analyses stratified by histologic subtype for each exposure of interest. We did not consider comorbidities; however, we and others have shown that women with a diagnosis of ovarian cancer are likely to die of their disease. In our cohort, $>80 \%$ of deaths were attributed to ovarian cancer (Kotsopoulos et al, 
2016). In addition, the BMI calculation was based on selfreported weight and height; however, both measures have been shown to be highly valid and well-correlated with measured weight and height in previous studies (Kushi et al, 1988; Rimm et al, 1990). Furthermore, because of the length in time between diagnosis date and interview time, the potential for recall bias may impact our findings. Importantly, information on the extent of residual disease after primary debulking surgery (an important prognostic factor) was available for only 59\% of the patients. However, we displayed our findings both with (model 2) and without (model 1) adjustment for this variable. In most instances, findings were strengthened in the fully adjusted model and a strength of this study was the ability to adjust for residual disease status, whereas previously published studies have not. Additional strengths of our study included the large number of unselected patients of epithelial ovarian cancer with detailed information on cause of death (ovarian cancer specific), as well as on tumour characteristics, allowing for a relatively wellpowered and detailed analysis. We performed a left-truncated survival analysis whereby each subject only contributes personyears from the date of genetic testing, minimising the extent of survivorship bias that we have previously reported in our cohort (Narod et al, 2013).

In summary, our findings confirm that parity is associated with improved ovarian cancer survival, whereas BMI and smoking is associated with decreased survival. Whether or not postdiagnostic changes in exposures or lifestyle factors similarly affect survival is not known. Despite the well-described aetiologic roles of various hormonal and reproductive exposures on ovarian cancer risk, we observed no significant prognostic associations for the majority of these exposures. The findings from this study reiterate that once a woman is diagnosed with ovarian cancer, surgical debulking to achieve no residual disease likely has the most impact on her longterm survival.

\section{ACKNOWLEDGEMENTS}

Joanne Kotsopoulos is the recipient of a Cancer Care Ontario Research Chair in Population Studies and a Canadian Cancer Society Career Development Award in Prevention. Steven Narod is the recipient of a Canada Research Chair tier I. This study was supported by US National Institutes of Health Grants R01CA063678 (Narod) and R01-CA063682 (Risch).

\section{CONFLICT OF INTEREST}

The authors declare no conflict of interest.

\section{REFERENCES}

Allison P (1995) Survival Analysis using SAS: A Practical Guide. SAS Institute Inc.: Cary, NC, USA.

Barakat RR, Berchuck A, Markman M, Randall ME (2009) Principles and Practice of Gynecologic Oncology. Lippincott Williams and Wilkins: Baltimore, MD, USA.

Beral V, Doll R, Hermon C, Peto R, Reeves G (2008) Ovarian cancer and oral contraceptives: collaborative reanalysis of data from 45 epidemiological studies including 23257 women with ovarian cancer and 87303 controls. Lancet 371: 303-314.

Besevic J, Gunter MJ, Fortner RT, Tsilidis KK, Weiderpass E, Onland-Moret NC, Dossus L, Tjonneland A, Hansen L, Overvad K, Mesrine S, Baglietto L, Clavel-Chapelon F, Kaaks R, Aleksandrova K, Boeing H, Trichopoulou A, Lagiou P, Bamia C, Masala G, Agnoli C, Tumino R, Ricceri F, Panico S, Bueno-de-Mesquita HB, Peeters PH, Jareid M, Quiros JR, Duell EJ, Sanchez MJ, Larranaga N, Chirlaque MD, Barricarte A, Dias JA, Sonestedt E, Idahl A,
Lundin E, Wareham NJ, Khaw KT, Travis RC, Rinaldi S, Romieu I, Riboli E, Merritt MA (2015) Reproductive factors and epithelial ovarian cancer survival in the EPIC cohort study. Br J Cancer 113: 1622-1631.

Chang SJ, Bristow RE (2012) Evolution of surgical treatment paradigms for advanced-stage ovarian cancer: redefining 'optimal' residual disease. Gynecol Oncol 125: 483-492.

Chang SJ, Bristow RE, Chi DS, Cliby WA (2015) Role of aggressive surgical cytoreduction in advanced ovarian cancer. J Gynecol Oncol 26: 336-342. Collaborative Group on Epidemiological Studies of Ovarian CancerBeral V, Gaitskell K, Hermon C, Moser K, Reeves G, Peto R (2015) Menopausal hormone use and ovarian cancer risk: individual participant meta-analysis of 52 epidemiological studies. Lancet 385: 1835-1842.

Cramer DW, Welch WR, Scully RE, Wojciechowski CA (1982) Ovarian cancer and talc: a case-control study. Cancer 50: 372-376.

Cramer DW, Xu H (1995) Epidemiologic evidence for uterine growth factors in the pathogenesis of ovarian cancer. Ann Epidemiol 5: 310-314.

Danforth KN, Tworoger SS, Hecht JL, Rosner BA, Colditz GA, Hankinson SE (2007) A prospective study of postmenopausal hormone use and ovarian cancer risk. Br J Cancer 96: 151-156.

du Bois A, Reuss A, Pujade-Lauraine E, Harter P, Ray-Coquard I, Pfisterer J (2009) Role of surgical outcome as prognostic factor in advanced epithelial ovarian cancer: a combined exploratory analysis of 3 prospectively randomized phase 3 multicenter trials: by the Arbeitsgemeinschaft Gynaekologische Onkologie Studiengruppe Ovarialkarzinom (AGOOVAR) and the Groupe d'Investigateurs Nationaux Pour les Etudes des Cancers de l'Ovaire (GINECO). Cancer 115: 1234-1244.

Fathalla MF (1971) Incessant ovulation-a factor in ovarian neoplasia? Lancet 2: 163 .

Fleming JS, Beaugie CR, Haviv I, Chenevix-Trench G, Tan OL (2006) Incessant ovulation, inflammation and epithelial ovarian carcinogenesis: revisiting old hypotheses. Mol Cell Endocrinol 247: 4-21.

Fortner RT, Ose J, Merritt MA, Schock H, Tjonneland A, Hansen L, Overvad K, Dossus L, Clavel-Chapelon F, Baglietto L, Boeing H, Trichopoulou A, Benetou V, Lagiou P, Agnoli C, Mattiello A, Masala G, Tumino R, Sacerdote C, Bueno-de-Mesquita HB, Onland-Moret NC, Peeters PH, Weiderpass E, Torhild Gram I, Duell EJ, Larranaga N, Ardanaz E, Sanchez MJ, Chirlaque MD, Brandstedt J, Idahl A, Lundin E, Khaw KT, Wareham N, Travis RC, Rinaldi S, Romieu I, Gunter MJ, Riboli E, Kaaks R (2015) Reproductive and hormone-related risk factors for epithelial ovarian cancer by histologic pathways, invasiveness and histologic subtypes: Results from the EPIC cohort. Int J Cancer 137: 1196-1208.

Kotsopoulos J, Moody JR, Fan I, Rosen B, Risch HA, Mclaughlin JR, Sun P, Narod SA (2012) Height, weight, BMI and ovarian cancer survival. Gynecol Oncol 127(1): 83-87.

Kotsopoulos J, Rosen B, Fan I, Moody J, Mclaughlin JR, Risch H, May T, Sun P, Narod SA (2016) Ten-year survival after epithelial ovarian cancer is not associated with BRCA mutation status. Gynecol Oncol 140: 42-47.

Kushi LH, Kaye SA, Folsom AR, Soler JT, Prineas RJ (1988) Accuracy and reliability of self-measurement of body girths. Am J Epidemiol 128: 740-748.

La Vecchia C (2016) Ovarian cancer: epidemiology and risk factors. Eur J Cancer Prev.

Luan NN, Wu QJ, Gong TT, Vogtmann E, Wang YL, Lin B (2013) Breastfeeding and ovarian cancer risk: a meta-analysis of epidemiologic studies. Am J Clin Nutr 98: 1020-1031.

Mclaughlin JR, Rosen B, Moody J, Pal T, Fan I, Shaw PA, Risch HA, Sellers TA, Sun P, Narod SA (2013) Long-term ovarian cancer survival associated with mutation in BRCA1 or BRCA2. J Natl Cancer Inst 105: 141-148.

Moorman PG, Schildkraut JM, Calingaert B, Halabi S, Vine MF, Berchuck A (2002) Ovulation and ovarian cancer: a comparison of two methods for calculating lifetime ovulatory cycles (United States). Cancer Causes Control 13: 807-811.

Nagle CM, Bain CJ, Green AC, Webb PM (2008) The influence of reproductive and hormonal factors on ovarian cancer survival. Int $J$ Gynecol Cancer 18: 407-413.

Narod S (2015) Can advanced stage ovarian cancer be cured? Nat. Rev Clin Oncol 13: 255-261.

Narod SA, Moody JR, Rosen B, Fan I, Risch A, Sun P, Mclaughlin JR (2013) Estimating survival rates after ovarian cancer among women tested for BRCA1 and BRCA2 mutations. Clin Genet 83: 232-237.

Ness RB, Cottreau C (1999) Possible role of ovarian epithelial inflammation in ovarian cancer. J Natl Cancer Inst 91: 1459-1467. 
Ness RB, Grisso JA, Cottreau C, Klapper J, Vergona R, Wheeler JE, Morgan M, Schlesselman JJ (2000) Factors related to inflammation of the ovarian epithelium and risk of ovarian cancer. Epidemiology 11: 111-117.

Pearce CL, Templeman C, Rossing MA, Lee A, Near AM, Webb PM, Nagle CM, Doherty JA, Cushing-Haugen KL, Wicklund KG, Chang-Claude J, Hein R, Lurie G, Wilkens LR, Carney ME, Goodman MT, Moysich K, Kjaer SK, Hogdall E, Jensen A, Goode EL, Fridley BL, Larson MC, Schildkraut JM, Palmieri RT, Cramer DW, Terry KL, Vitonis AF, Titus LJ, Ziogas A, Brewster W, Anton-Culver H, Gentry-Maharaj A, Ramus SJ, Anderson AR, Brueggmann D, Fasching PA, Gayther SA, Huntsman DG, Menon U, Ness RB, Pike MC, Risch H, Wu AH, Berchuck A (2012) Association between endometriosis and risk of histological subtypes of ovarian cancer: a pooled analysis of case-control studies. Lancet Oncol 13: 385-394.

Poole EM, Konstantinopoulos PA, Terry KL (2016) Prognostic implications of reproductive and lifestyle factors in ovarian cancer. Gynecol Oncol 142: $574-587$.

Poole EM, Merritt MA, Jordan SJ, Yang HP, Hankinson SE, Park Y, Rosner BA, Webb PM, Cramer DW, Wentzensen N, Terry KL, Tworoger SS (2013) Hormonal and reproductive risk factors for epithelial ovarian cancer by tumor aggressiveness. Cancer Epidemiol Biomarkers Prev 22: $429-437$.

Rimm EB, Stampfer MJ, Colditz GA, Chute CG, Litin LB, Willett WC (1990) Validity of self-reported waist and hip circumferences in men and women. Epidemiology 1: 466-473.

Risch HA (1998) Hormonal etiology of epithelial ovarian cancer, with a hypothesis concerning the role of androgens and progesterone. [comment]. J Natl Cancer Inst 90: 1774-1786.

Robbins CL, Whiteman MK, Hillis SD, Curtis KM, Mcdonald JA, Wingo PA, Kulkarni A, Marchbanks PA (2009) Influence of reproductive factors on mortality after epithelial ovarian cancer diagnosis. Cancer Epidemiol Biomarkers Prev 18: 2035-2041.

Shafrir AL, Babic A, Tamimi RM, Rosner BA, Tworoger SS, Terry KL (2016) Reproductive and hormonal factors in relation to survival and platinum resistance among ovarian cancer cases. Br J Cancer 115: 1391-1399.

Shan W, Liu J (2009) Inflammation: a hidden path to breaking the spell of ovarian cancer. Cell Cycle 8: 3107-3111.

Sopik V, Iqbal J, Rosen B, Narod SA (2015) Why have ovarian cancer mortality rates declined? Part II. Case-fatality. Gynecol Oncol 138: $750-756$.

Terry KL, Karageorgi S, Shvetsov YB, Merritt MA, Lurie G, Thompson PJ, Carney ME, Weber RP, Akushevich L, Lo-Ciganic WH, Cushing-Haugen K, Sieh W, Moysich K, Doherty JA, Nagle CM, Berchuck A, Pearce CL, Pike M, Ness RB, Webb PM, Rossing MA, Schildkraut J, Risch H, Goodman MT (2013) Genital powder use and risk of ovarian cancer: a pooled analysis of 8,525 cases and 9,859 controls. Cancer Prev Res (Phila) 6: $811-821$.
Trabert B, Ness RB, Lo-Ciganic WH, Murphy MA, Goode EL, Poole EM, Brinton LA, Webb PM, Nagle CM, Jordan SJ. Australian Ovarian Cancer Study Group, Australian Cancer Study (Ovarian Cancer)Risch HA, Rossing MA, Doherty JA, Goodman MT, Lurie G, Kjaer SK, Hogdall E, Jensen A, Cramer DW, Terry KL, Vitonis A, Bandera EV, Olson S, King MG, Chandran U, Anton-Culver H, Ziogas A, Menon U, Gayther SA, Ramus SJ, Gentry-Maharaj A, Wu AH, Pearce CL, Pike MC, Berchuck A, Schildkraut JM, Wentzensen N. Ovarian Cancer Association Consortium (2014) Aspirin, nonaspirin nonsteroidal anti-inflammatory drug, and acetaminophen use and risk of invasive epithelial ovarian cancer: a pooled analysis in the Ovarian Cancer Association Consortium J Natl Cancer Inst 106: djt431.

Wentzensen N, Poole EM, Trabert B, White E, Arslan AA, Patel AV, Setiawan VW, Visvanathan K, Weiderpass E, Adami HO, Black A, Bernstein L, Brinton LA, Buring J, Butler LM, Chamosa S, Clendenen TV, Dossus L, Fortner R, Gapstur SM, Gaudet MM, Gram IT, Hartge P, Hoffman-Bolton J, Idahl A, Jones M, Kaaks R, Kirsh V, Koh WP, Lacey Jr JV, Lee IM, Lundin E, Merritt MA, Onland-Moret NC, Peters U, Poynter JN, Rinaldi S, Robien K, Rohan T, Sandler DP, Schairer C, Schouten LJ, Sjoholm LK, Sieri S, Swerdlow A, Tjonneland A, Travis R, Trichopoulou A, van den Brandt PA, Wilkens L, Wolk A, Yang HP, Zeleniuch-Jacquotte A, Tworoger SS (2016) Ovarian Cancer risk factors by histologic subtype: an analysis from the Ovarian Cancer Cohort Consortium. J Clin Oncol 34: 2888-2898.

Whittemore AS, Harris R, Itnyre J (1992) Characteristics relating to ovarian cancer risk: collaborative analysis of 12 US case-control studies. IV. The pathogenesis of epithelial ovarian cancer. Collaborative Ovarian Cancer Group. Am J Epidemiol 136: 1212-1220.

Zhang S, Royer R, Li S, Mclaughlin JR, Rosen B, Risch HA, Fan I, Bradley L, Shaw PA, Narod SA (2011) Frequencies of BRCA1 and BRCA2 mutations among 1,342 unselected patients with invasive ovarian cancer. Gynecol Oncol 121: 353-357.

Zhou B, Sun Q, Cong R, Gu H, Tang N, Yang L, Wang B (2008) Hormone replacement therapy and ovarian cancer risk: a meta-analysis. Gynecol Oncol 108: 641-651.

Zhou Y, Chlebowski R, Lamonte MJ, Bea JW, Qi L, Wallace R, Lavasani S, Walsh BW, Anderson G, Vitolins M, Sarto G, Irwin ML (2014) Body mass index, physical activity, and mortality in women diagnosed with ovarian cancer: results from the Women's Health Initiative. Gynecol Oncol 133: $4-10$.

This work is published under the standard license to publish agreement. After 12 months the work will become freely available and the license terms will switch to a Creative Commons AttributionNonCommercial-Share Alike 4.0 Unported License. 